\title{
Sodium-glucose cotransporter type 2 inhibitors: A new era in the pharmacological treatment of heart failure with reduced ejection fraction?
}

\author{
Yaniel Castro-Torres ${ }^{1 *}$ and Richard E. Katholi ${ }^{2}$ \\ ${ }^{1}$ Servicio de Cardiología, Hospital Universitario Celestino Hernández Robau. Santa Clara, Villa Clara, Cuba \\ ${ }^{2}$ Department of Pharmacology, Southern Illinois School of Medicine, USA
}

\begin{abstract}
In the past decades a wide number of drugs have been approved for the treatment of heart failure. Sacubritil/valsartan and ivabradine have been the most recent drugs included for the management of heart failure with reduced ejection fraction. Nowadays, sodium glucose cotransporter type 2 inhibitors have emerged as a feasible choice for the treatment of type 2 diabetic patients with heart failure. These drugs have demonstrated to reduce the risk of hospitalization in patients with heart failure and recent data suggest that these outcomes can be also seen in non-diabetic patients. These promising outcomes will open the possibility that these drugs could be approved for the treatment of heart failure in diabetic patients and a new era in the management of this condition is advised.
\end{abstract}

In the past decades, heart failure (HF) has become one of the most studied conditions worldwide. In the spectrum of HF, HF with reduced ejection fraction ( $\mathrm{HFrEF}$ ) is associated with significant risk of mortality and most patients have a bad prognosis after initial diagnosis [1].

At the beginning of 90's decade, the first studies demonstrating a reduction in mortality in HFrEF patients with the use of angiotensin converting enzyme inhibitors were published [2]. After that, medical community saw as a group of randomized controlled trials revealed that evidence-based beta-blockers [3] and mineralocorticoid receptor antagonist [4] therapy reduced the risk of mortality and improved quality of life in these patients (Figure 1).

This group of drugs represents the first line for the treatment of HFrEF with diuretics, digitalis and hydralazine/isosorbide as a secondand third-line treatment [5]. Despite these advances, the prognosis of patients with HFrEF remains guarded.

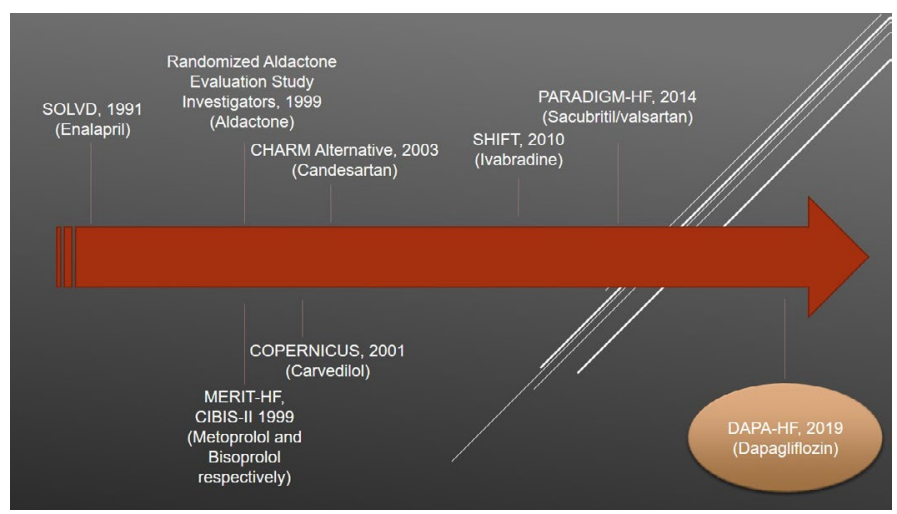

Figure 1. Some drugs approved for the treatment of HFrEF before the publication of DAPA-HF trial
After some years of investigation, in 2014 were published the results of the PARADIGM-HF trial [6]. This trial opens a new perspective for HF patients. A total of 8442 patients with $\mathrm{HFrEF}$ were randomized to receive enalapril or sacubritil/valsartan. After a follow-up of 27 months, the study was stopped early because of net benefits with sacubritil/ valsartan over enalapril in HF patients. Those patients taking sacubritil/ valsartan had a reduced risk of death and of hospitalization for HF. In the next years, several post-hoc analysis of PARADIGM-HF trial and new studies have demonstrated the benefits of sacubritil/valsartan in HF patients with an improvement in clinical, hemodynamic and biochemical parameters $[7,8]$. Actually, sacubritil/valsartan is approved by the practice guidelines of the American College of Cardiology/ American Heart Association [9] and European Society of Cardiology [10] as a class IB for reducing mortality and improving symptoms in patients with HFrEF who remain symptomatic after maximum tolerated doses of angiotensin converting enzyme inhibitors/angiotensin receptor antagonists, evidence-based beta-blockers and mineralocorticoid receptor antagonists.

Ivabradine, a selective inhibitor of $\mathrm{f}$-channels within the sinoatrial node has been accepted as a treatment in HFrEF patients. After the outcomes of two seminal trials, BEAUTIFUL [11] and SHIFT [12], in which ivabradine was demonstrated to reduce HF hospitalizations and an improvement in patients' quality of life, this drug has been included as a choice in patients with HFrEF, sinus rhythm and heart rate over

${ }^{*}$ Correspondence to: Yaniel Castro-Torres, Servicio de Cardiología, Hospital Universitario Celestino Hernández Robau. Santa Clara, Villa Clara, Cuba, E-mail: castrotorresy@gmail.com

Key words: Heart failure, heart failure reduced ejection fraction, heart failure management, sodium glucose cotransporter type 2 inhibitors

Received: November 28, 2019; Accepted: December 16, 2019; Published: December 24, 2019 
70 beats per minute. Both sacubritil/valsartan and ivabradine have been the most recent approved drugs for HFrEF treatment. However, investigations to find new drugs to treat these patients are ongoing with promising results.

Sodium-glucose cotransporter type 2 inhibitors, the most recent approved hypoglicemic drugs have been associated with a reduced risk of HF hospitalization. Three large randomized controlled trial (EMPAREG-OUTCOMES [13], CANVAS [14] and DECLARE TIMI 58 [15]) evaluated the safety and benefits of empagliflozin, canagliflozin and dapagliflozin respectively in type 2 diabetic patients with high cardiovascular risk. As a second end point, these drugs were associated with a reduced risk of HF hospitalizations. No significant differences in side effects were seen in patients taking sodium-glucose cotransporter type 2 inhibitors compared to placebo. The most recent study on these drugs was DAPA-HF [16]. This study evaluated the use of dapagliflozin in 4744 patients with HFrEF (left ventricular ejection fraction of $40 \%$ or less), New York Heart Association II-IV to receive dapagliflozin or placebo. All patients were receiving guide-based recommended therapy. After a median follow-up of 18.2 month, the composite end point of worsening HF or cardiovascular death was significantly reduced in the dapagliflozin group (HR: 0.74; 95\% IC: $0.65-0.85$; $\mathrm{p}<0.001$ ). These findings were similar in patients with and without diabetes mellitus.

Results of DAPA-HF have generated a great debate in the medical community about the benefits of sodium-glucose cotransporter type 2 inhibitors in patients with HF. This group of drugs, beyond hypoglycemic effects also have diuretic, natriuretic, antihypertensive, anti-inflammatory and antiremodelling effects which could explain in part, the positive outcomes in HF patients [17]. Additionally, sodiumglucose cotransporter type 2 inhibitors have been demonstrated to reduce the risk of kidney failure and cardiovascular events in type 2 diabetic patients with kidney disease [18] and improve left ventricular diastolic functional parameters in type 2 diabetic patients and HF [19].

After these results, sodium-glucose cotransporter type 2 inhibitors may represent the first line for treating patients with type 2 diabetes mellitus and HFrEF. However, if these drugs will constitute also a recommendation in HFrEF patients without diabetes needs further investigation. At this time, the main concern for the use of sodiumglucose cotransporter type 2 inhibitors in non-diabetic patients is the risk of hypoglycemia.

Although the definitive inclusion of sodium-glucose cotransporter type 2 inhibitors as an alternative for treating HFrEF patients' needs more investigation, the positive results of EMPA-REG OUTCOME, CANVAS, TIMI 58 and the most recent DAPA-HF could represent a new era in the treatment of HFrEF patients.

In conclusion, HFrEF has a complex pathophysiology and the use of several drugs with different mechanisms of action and working in multiple pathways is necessary. The medical community is looking forward to a new era in the development of HFrEF treatments. These new alternatives and others under investigation will likely result in higher survival and better quality of life of our patients.

\section{References}

1. Chioncel O, Lainscak M, Seferovic PM, Anker SD, Crespo-Leiro MG, et al. (2017) Epidemiology and one-year outcomes in patients with chronic heart failure and preserved, mid-range and reduced ejection fraction: an analysis of the ESC Heart Failure Long-Term Registry. Eur J Heart Fail 19: 1574-1585. [Crossref]
2. SOLVD Investigators, Yusuf S, Pitt B, Davis CE, Hood WB, et al. (1991) Effect of enalapril on survival in patients with reduced left ventricular ejection fractions and congestive heart failure. $N$ Engl J Med 325: 293-302. [Crossref]

3. No authors listed (1999) Effect of metoprolol CR/XL in chronic heart failure Metoprolol CR/XL Randomised Intervention Trial in Congestive Heart Failure (MERIT-HF). Lancet 353: 2001-2007. [Crossref]

4. Pitt B, Zannad F, Remme WJ, Cody R, Castaigne A, et al. (1999) The effect of spironolactone on morbidity and mortality in patients with severe heart failure. Randomized Aldactone Evaluation Study Investigators. N Engl J Med 341: 709-717. [Crossref]

5. Katholi RE, Castro-Torres Y, Ervin MR (2019) Pharmacological â€œgame changersâ€ for HFrEF patients. J Cardio Res 2: 15

6. McMurray JJ, Packer M, Desai AS, Gong J, Lefkowitz MP, et al. (2014) Angiotensinneprilysin inhibition versus enalapril in heart failure. N Engl J Med 371: 993-1004. [Crossref]

7. Solomon SD, Claggett B, Desai AS, Packer M, Zile M, et al. (2016) Influence of Ejection Fraction on Outcomes and Efficacy of Sacubitril/Valsartan (LCZ696) in Heart Failure with Reduced Ejection Fraction: The Prospective Comparison of ARNI with ACEI to Determine Impact on Global Mortality and Morbidity in Heart Failure (PARADIGM-HF) Trial. Circ Heart Fail 9: e002744. [Crossref]

8. Martens P, Belien H, Dupont M, Mullens W (2018) Insights into implementation of sacubitril/valsartan into clinical practice. ESC Heart Fail 5: 275-283. [Crossref]

9. Yancy CW, Jessup M, Bozkurt B, Butler J, Casey DE Jr, et al. (2017) 2017 ACC/ AHA/HFSA Focused Update of the 2013 ACCF/AHA Guideline for the Management of Heart Failure: A Report of the American College of Cardiology/American Heart Association Task Force on Clinical Practice Guidelines and the Heart Failure Society of America. Circulation 136: e137-e161. [Crossref]

10. Ponikowski P, Voors AA, Anker SD, Bueno H, Cleland JG, et al. (2016) 2016 ESC Guidelines for the diagnosis and treatment of acute and chronic heart failure: The Task Force for the diagnosis and treatment of acute and chronic heart failure of the European Society of Cardiology (ESC). Developed with the special contribution of the Heart Failure Association (HFA) of the ESC. Eur J Heart Fail 18: 891-975. [Crossref]

11. Fox K, Ford I, Steg PG, Tendera M, Ferrari R, et al. (2008) Ivabradine for patients with stable coronary artery disease and left-ventricular systolic dysfunction (BEAUTIFUL) a randomised, double-blind, placebo-controlled trial. Lancet 372: 807-816. [Crossref]

12. Swedberg K, Komajda M, Bohm M, Borer JS, Ford I, et al. (2010) Ivabradine and outcomes in chronic heart failure (SHIFT): a randomised placebo-controlled study. Lancet 376: 875-885. [Crossref]

13. Zinman B, Wanner C, Lachin JM, Fitchett D, Bluhmki E, et al. (2015) Empagliflozin, Cardiovascular Outcomes, and Mortality in Type 2 Diabetes. N Engl J Med 373: 2117 2128. [Crossref]

14. Neal B, Perkovic V, Mahaffey KW, de Zeeuw D, Fulcher G, et al. (2017) Canagliflozin and Cardiovascular and Renal Events in Type 2 Diabetes. N Engl J Med 377: 644-657. [Crossref]

15. Wiviott SD, Raz I, Bonaca MP, Mosenzon O, Kato ET, et al. (2019) Dapagliflozin and Cardiovascular Outcomes in Type 2 Diabetes. N Engl J Med 380: 347-357. [Crossref]

16. McMurray JJV, Solomon SD, Inzucchi SE, Kober L, Kosiborod MN, et al. (2019) Dapagliflozin in Patients with Heart Failure and Reduced Ejection Fraction. $N$ Engl $J$ Med 381: 1995-2008. [Crossref]

17. Ghosh RK, Ghosh GC, Gupta M, Bandyopadhyay D, Akhtar T, et al. (2019) Sodium Glucose Co-transporter 2 Inhibitors and Heart Failure. Am J Cardiol 124: 1790-1796.

18. Perkovic V, Jardine MJ, Neal B, Bompoint S, Heerspink HJL, et al. (2019) Canagliflozin and Renal Outcomes in Type 2 Diabetes and Nephropathy. $N$ Engl J Med 380: 22952306. [Crossref]

19. Soga F, Tanaka H, Tatsumi K, Mochizuki Y, Sano H, et al. (2018) Impact of dapagliflozin on left ventricular diastolic function of patients with type 2 diabetic mellitus with chronic heart failure. Cardiovasc Diabetol 17: 132. [Crossref]

Copyright: (C2019 Castro-Torres Y. This is an open-access article distributed under the terms of the Creative Commons Attribution License, which permits unrestricted use, distribution, and reproduction in any medium, provided the original author and source are credited. 